\title{
Learning psychology as a challenging process towards development as well as "studies as usual": a thematic analysis of medical students' reflective writing
}

\author{
This article was published in the following Dove Press journal: \\ Advances in Medical Education and Practice \\ 12 December 2014 \\ Number of times this article has been viewed
}

\author{
Olof Semb' \\ Niclas Kaiser ${ }^{2}$ \\ Sven-Olof Andersson' \\ Elisabet Sundbom ${ }^{3}$ \\ 'Department of Clinical Sciences, \\ Division for Professional \\ Development, Umeå University, Umeå, \\ Sweden; '2Department of Psychology, \\ Umeå University, Umeå, Sweden; \\ ${ }^{3}$ Department of Clinical Sciences, \\ Division for Psychiatry and Medical \\ Psychology, Umeå University, \\ Umeå, Sweden
}

\begin{abstract}
Reflective writing in medical training has been shown to be most effective when combined with some form of personal meeting or dialog. During a course in medical psychology for medical students, reflective texts were followed up by an individual personal talk with a teacher from the course. Thematic analysis of the texts revealed four separate sub-themes: 1) the course has enabled me and the class to develop, which is good albeit arduous; 2) understanding myself is a resource in understanding people as well as knowing psychology; 3) the course provided me with new, purely intellectual skills as well as eye-openers; and 4) the receiving teacher is an integral part of my reflective writing. The main theme, capturing the students' writing process, concluded that students perceive the course as "Learning psychology as a challenging process towards development" as well as "studies as usual". Ethical, psychological, and pedagogical aspects are discussed in the paper.
\end{abstract}

Keywords: reflective writing, self-knowledge, individual personal talks, thematic analysis, medical education

\section{Introduction}

Medical doctors are assumed to have certain skills and indeed some of these skills or abilities are prerequisites for competence and success, ie, requirements for being a "good doctor". Usually, with varying definitions, this is discussed as professionalism. ${ }^{1}$ These skills and abilities include empathy and interpersonal skills, reflective ability, collegiality, affective competence, and clinical knowledge. While the importance of integrating professionalism into the curriculum is well established, ${ }^{2}$ it has further been argued that, first and foremost, measurable behaviors are relevant parts of the curriculum. ${ }^{3}$ Self-awareness and reflective ability are important aspects of professionalism and professional behavior. ${ }^{2,3}$

Many of these professional skills are discussed within the field of normal psychology and courses in psychology can provide useful insights in these regards. ${ }^{4}$ Current research $^{5}$ speaks clearly about how knowledge of normal psychological phenomena contributes to medical education. That is, knowledge about psychological normal phenomena is an important part of being a competent doctor, as described earlier. Achieving this is a training process that includes many parts and topics, where professional development is an integral part. Psychological phenomena are, in turn, an important part of the professional development syllabus.
Correspondence: Olof Semb Department of Clinical Sciences, Umeå University Hospital, SE-90I 87 Umeå, Sweden Tel +46907856493

Email olof.semb@psychiat.umu.se 
Reflection can be a way to increase self-knowledge ${ }^{6}$ contributing to increasing medical students' professionalism. ${ }^{7,8}$ Reflective writing has been used in many studies and when used in medical training it has been described as successful. ${ }^{9-11}$ In general, reflective writing can be described as using student-generated text as a means to facilitate reflection and can be in the form of a logbook, free essays, or reports after specific incidents. When reflective writing is combined with some form of dialog, a meeting, or feedback, where someone else has read the text the most effective reflection seems to take place. ${ }^{12}$ Reflection in medical training is becoming increasingly more common ${ }^{10}$ and has been proven to be feasibly assessable. ${ }^{13}$ Self-knowledge is now part of the national expected learning outcomes for medical training in Sweden, ${ }^{14}$ and in other countries as well, ${ }^{15}$ and has been proven to be not only measurable but one of the most important aspects of professional behavior in medicine. ${ }^{3}$

Reflection has been described as an intellectual as well as an affective activity where practitioners critically analyze and evaluate experiences in order to gain new understanding; in clinical settings this also leads to an appreciation of the way one thinks and acts. ${ }^{9}$ It has been argued that reflection is often misunderstood or even overlooked in current medical teaching. ${ }^{16}$ Dewey ${ }^{17}$ explicitly stated that reflection is always associated with some amount of effort and a willingness to approach uncertainty; thus, establishing that reflection is more than just thinking about something. That is, one can think reflectively only when one is willing to endure suspense and to undergo the trouble of searching.

Medical training and teaching has been shown to be both beneficial and unfavorable for students' personal development, where education can have a reinforcing and positive as well a restraining and negative impact on students' personalities. ${ }^{18}$ Medical training starts a developmental process without necessarily offering the support needed during such a transition. Medical students are required, not only to acquire knowledge and medical skills, but also achieve psychological growth without the psychological and pedagogical support necessary for this. It can be argued that in order to engage in efficient self-reflection, students first need to acquire the fundamental concepts of psychology; acquiring the concepts leads, via understanding, to the potential of development and growth.

At Umeå University this process is started while simultaneously offering support for this development. One of these support mechanisms takes place during the course in Medical Psychology. This is a 3-week introductory course in Medical Psychology for third year medical students, on their last pre-clinical semester. Very few have studied universitylevel psychology before the course. The curriculum aims at integrating and synthesizing psychological theories discussed during the course. Reflection is an integral part of the course curriculum in medical psychology, and the students are encouraged to apply the normal psychological theories on themselves and their individual life histories, as self-knowledge is one of the expected learning outcomes of the course. Psychological perspectives are presented during the course in the form of a selection of theories, including: affect theory, attachment theory, psychodynamic and cognitive-behavioral personality theories, aging and existential perspectives, group psychology and family dynamics, and lastly theory regarding crisis as well as practical psychosomatics. These perspectives are covered in the form of lectures followed by mandatory case seminars. Outside lectures, students are obliged to write a mandatory individual reflective text each week of the course. While submitting the texts is mandatory, the texts themselves are not graded, ie, no assessment of the quality of the text takes place. The texts are submitted to one of the teachers (a clinical psychologist or medical doctor with psychotherapy training). The students are allowed a great degree of freedom in relation to what they write. The instructions encourage students to reflect on, for example, their own history, personal relationships and their considerations regarding future professional behavior. In line with the course curriculum, aiming at increased self-knowledge through reflection, the students are also encouraged to use the psychological theories in their writing. After the last lecture, each student is required to meet the teacher who received the written reflections for a 45 minutes mandatory individual reflective talk (the texts are never used during lectures or seminars). The talk has elements of supportive as well as insight-oriented processes, where the students are encouraged to reflect together with the teacher on their own texts and on their own self. The students are in charge of the choice of perspective (ie, what is discussed) and the level of privacy (eg, emotional involvement) during this talk. If students experience psychological problems evoked by/during the course or express needs for counseling during the talk, the teachers refer them to the student health services on campus. In rare, more acute cases, contact with the on-call psychiatrist can be provided by the teacher.

Evaluations of the course, based on 275 students, published recently ${ }^{14}$ showed that students supported the idea that this pedagogical method increases self-awareness, curiosity, and professional reflexivity; between $65 \%$ and $75 \%$ of responders fully agreed that the course led to increased self-knowledge, an increase in curiosity about oneself, as well as increased 
self-knowledge in relation to future doctor-patient meetings. Between $70 \%$ and $90 \%$ fully agreed that the reflective writing and the individual personal talk had helped them to better understand one or more personal issues as well as having been meaningful in their developmental process. The personal talks were described as developing, important, and respectful. In sum, the student evaluations of the combination of reflective writing and a student-teacher dialog were very positive, indicating a strong support for the usefulness and popularity of this feature.

Being a novel and important pedagogical method, little is known about how the learning process relates to selfawareness. The question presents itself: what is there to be learned by analyzing the texts produced by students engaged in reflective writing?

\section{Aims}

The aim of this study was to increase our understanding about students' experiences of the combination of reflective writing and a student-teacher dialog in medical psychology in medical teaching. A specific aim was to explore what students chose to write about.

\section{Method}

\section{Procedure and participants}

The data in this study are texts collected over the course of a 3-week class in Medical Psychology for third year medical students, on their last pre-clinical semester. During the course, the students are asked to write a reflective text where they discuss the contents of the course as it relates to their own personality, personal history etc. The instruction is deliberately open and free, enabling students to express themselves unreservedly and variably. The recipient of the texts is known from the beginning, since all students are assigned to one of the teachers in the course (for the present study, four teachers). The students are obliged to deliver one text each week of the course, with a limit of 2-3 pages per week and emphasis is placed on the level of confidentiality maintained between the individual student and the assigned teacher. During the course, the texts are used solely for the purpose of the talk and are later destroyed. For the present study, however, the texts used in the analysis were not destroyed and were preserved in accordance with national research guidelines.

For the present study, informed consent was obtained by first providing information about the study design, ethics, and purpose, both verbally and in written form to students during the reflective talks. The students were encouraged to think it through thoroughly and report their decision afterward, rather than agreeing or disagreeing immediately. Effort was placed on stressing that participation was voluntary. Students who gave their consent within a week were included in the sampling procedure. From the cohort of students (aged 20-44, median age: $24 ; 2 / 3$ female students) agreeing to participate with their texts (a total of 128 letters) in the qualitative analysis, each teacher randomly selected eight texts (each consisting of three weekly written reflections), which resulted in a total of 32 texts being used for the analysis. The analysis was based on approximately 100,000 words. The texts were de-identified prior to the analysis.

The study was approved by the Regional Ethical Review Board in Umeå (D.No: 2010-268-31Ö).

\section{Analysis}

Though each text consisted of three letters, it was treated as one continuous text. The analysis process was in accordance with qualitative content analysis, as described by Graneheim and Lundman ${ }^{19}$ and interpretative phenomenological analysis, ${ }^{20}$ using a procedure of condensing, coding, and categorizing while retaining contact with raw data. An example is shown in Table 1. All 32 texts in the sample were read by all authors. After familiarizing with the texts, the content from one letter was condensed and coded by each author, followed by a discussion regarding the coding in order to gain inter-coder agreement. This procedure was followed by finalizing the coding of all texts individually, eight texts each. The first and second author created preliminary categories, using the codes from all 32 texts. Categories were then finalized during a discussion among all coauthors. During the whole analysis process, the authors encouraged differences in opinion, and whenever disagreement occurred, discussion took place, aiming at reasonable consensus.

The preliminary categories retained their original formulation throughout the process in order to remain close to the actual wording of the participants. Categories were later renamed to describe the meaning of the codes that were included under

Table I Example of the abstraction process in the study, from raw text, into code, category and subtheme

\begin{tabular}{|c|c|c|c|}
\hline Text & Code & Category & Subtheme \\
\hline $\begin{array}{l}\text { I believe that the } \\
\text { purpose of psychology } \\
\text { is to simplify and } \\
\text { theorize human } \\
\text { behavior, in order to } \\
\text { better understand it } \\
\text { and using it to help } \\
\text { people }\end{array}$ & $\begin{array}{l}\text { The purpose of } \\
\text { psychology is to } \\
\text { understand and } \\
\text { to help people }\end{array}$ & $\begin{array}{l}\text { Insights } \\
\text { on a more } \\
\text { theoretical } \\
\text { level }\end{array}$ & $\begin{array}{l}\text { The course } \\
\text { gave new } \\
\text { purely } \\
\text { intellectual } \\
\text { skills and } \\
\text { eye-openers }\end{array}$ \\
\hline
\end{tabular}


each category. Categories were aggregated based on thematic similarity and the subthemes were formulated to capture the gist of these aggregated categories. Finally, a main theme was formulated, summarizing the four subthemes.

\section{Main results}

The analysis resulted in one main theme and four subthemes and these are presented in Table 2.

\section{Learning psychology as a challenging process towards development as well as "studies as usual"}

The main theme captures the dialectic in the four subthemes, as well as the dialectic of teaching and being taught psychology. This dialectic process is apparent in several ways. For instance, there are reports emphasizing purely theoretical understanding, not necessarily connected to personal development, but also descriptions of an arduous activity leading to personal development. A further dialectic deals with students' communications with the teacher, containing both specific theoretical as well as personal issues; the message to the teacher being either "teach me", on the one hand, or "help me" alternately "be gentle with me", on the other. The inclusion of "me", ie, one's own self, is presented as meaningful in many ways: on the one hand as using oneself to gain a deeper understanding of theory, and reversed, using theory to gain a deeper understanding of "me". Further, the inclusion of "me" in a developmental process leads to knowledge about the developmental process itself and, perhaps most importantly, the developmental process of others.

\section{Subtheme I: the course has enabled me and the class to develop, which is good albeit arduous}

The course was perceived as rewarding but hard, and the students reported having to think more than usual. At start, there

Table 2 Main theme and subthemes constructed through thematic analysis of students' $(n=32)$ reflective texts

\begin{tabular}{l} 
Main theme \\
Learning psychology as a challenging process toward development, \\
as well as "studies as usual" \\
Subthemes \\
The course has enabled me and the class to develop, which is good albeit \\
arduous \\
Understanding myself is a resource in understanding people as well as \\
knowing psychology \\
The course provided me with new, purely intellectual skills as well as \\
eye-openers \\
The receiving teacher is an integral part of my reflective writing \\
\hline
\end{tabular}

was some skepticism toward psychology, but acceptance for the subject grew over time and the students described a developing acceptance and awareness of, and attention to, one's own thoughts and reactions over time. While this development was perceived as surprising and unexpected, it was also described as stimulating.

The self-described personal development relates to different areas. Specifically, the course has led to increased ability to see how one's own life history relates to the current situation. The students describe that having to focus on personal experiences contributed to opportunities in making different connections without necessarily having all the answers. Students experience that the psychological tools provided by the course have yielded greater understanding of oneself and others, as well as an opportunity for further development:

\section{"These are things that I have carried inside that I have never been able to verbalize but now they have become easier to understand and possibly deal with"}

The students also experience that the class as a whole has evolved, for example by the fact that the group developed a new way of communicating; a new way of talking to one and other, studying each other, and to trying out new roles, especially as the students so far have studied in a context where principally factual knowledge has been promoted:

"When I reflect over our study group I think about what kind of group we are; we get along fine, there is room for conflict ... but we also shut people out. I just realized that as I wrote it down."

Reflective writing and personal talks were perceived as demanding: self-reflection was hard; to write was hard; and self-scrutiny was perceived as challenging. It was difficult for a variety of reasons and the fact that this was a new form of task also made it hard just to get started. Having to put their own reflections into words gave the reflections an added dimension of truth and reality, so merely expressing themselves in text and during talks was demanding and new:

"For a while I thought about submitting a letter with fabricated content, alternately one focusing only on subjects that don't affect me at all. That would have been the easy way out but I realize at the same time that that would have been foolish."

The taxing nature of the course also took physical expression in that students felt tired and exhausted; different 
expressions of having to "deal with" the course were evident. Some students also described that they were able to distance themselves from the subject by diminishing the validity and value of their own analyses and feelings, as well as the course itself.

\section{Subtheme 2: understanding myself is a resource in understanding people as well as knowing psychology} The students have, in their explorations of their own self, produced various descriptions of themselves, like "this is who I am", and "this is my life". Through these narratives, the students have also placed themselves in relation to the various norms regarding "sick" and "healthy", how a person is supposed to be and what it means to be normal:

"I see myself as a serious person. I have thought about it and I have decided that this is the kind of person I want to be!"

In relation to the beliefs about other people, the students also entertain thoughts about how it will work out for the student; what the student will be able to deal with as a private person and as a professional, when they now have realized that they have flaws and weaknesses. Students describe that this process of self-reflection has led to increased understanding and more nuanced views of other people's problems and life situations.

\section{Subtheme 3: the course provided me with new, purely intellectual skills as well as eye-openers}

The students also describe important realizations of more ordinary academic or intellectualized nature; these narratives include simple reports of thematic content from the course, but also descriptions of problems and dysfunction identified within them self or in others. The theoretical insights, whether simple or very complex, were often expressed eye-openers:

"It was interesting to learn that there are group processes going on all the time even though you are unaware of them. That was kind of an eye-opener for me."

The insights brought about a certain relief in individual students, but could also cause distress and a sense of loss of control; describing insights without yet having acquired tools for change, ie, knowing how things work but not necessarily how to make them better. The realizations led to an increased acceptance of psychology as a subject and its importance for medical education, while not necessarily providing increased knowledge about their own person, the professional role, or the circumstances of future patients. Rather, that knowledge could be generalized:

"Silence in a conversation can provoke anxiety, but in the doctor-patient relationship it is important to practice at allowing silence to occur."

\section{Subtheme 4: the receiving teacher is an integral part of my reflective writing}

Beside the narratives of the impact of the course on individual students and the student group, the texts also include the teacher as a recipient of the text. The students, for example, report specific expectations and suggestions for discrete topics to be discussed during their meeting with the teacher. Further they could describe feelings of concern and worry in anticipation of the meeting:

"For sure, I'm apprehensive over our meeting. I may come to find that something is wrong with me, but hopefully it will turn out well $\odot$;"

An important aspect of the inclusion of the self in relation to the teacher is that during the individual talks the students were given the opportunity to try on the role of patient, not just as role-play but actually revealing oneself and one's own thoughts and feelings.

\section{Discussion}

The purpose of this study was to investigate and compile relevant themes derived from reflective writing by medical students during their course in medical psychology. One of our main findings is that learning psychology through reflective writing, personal talks in combination with "teaching as usual", is productive but emotionally demanding for the students. It can be understood as something more than a purely academic pursuit, which presumably poses a "safer route". If the individual is to be "put under the loupe" in order to develop certain skills, it will lead to some concern as to what the individual will find. This concern can be traced to the, sometimes implicit, demands on medical students to develop empathy, reflection, and other skills, without really knowing what it entails. Central to our findings is that we have encountered a group of students who are highly motivated but, at the same time, apprehensive. This apprehensive position contains expectations of "I will study as usual and hear and learn stuff" as well as "things will happen to me". We assume that these expectations can, at least in part, be derived from communication between the pre-clinical students and their fellow students on later semesters, talking about the course. The Umeå students are introduced to psychology at 
what seems to be an opportune moment; they are about to start the clinical part of their training and their own ambivalence, caused by conflict between fear and apprehension on the one hand, and expectation and confidence on the other, provides motivation for reflection. Our results, however, suggest that the students' apprehensions and expectations before the course are quite reasonable, since much of what the students expect to happen, actually does happen. Furthermore, the students' texts clearly show that reflective activity is something more than merely thinking. ${ }^{9,17}$

The results show that the students' apprehension dissipates over time, and this seems mainly to be due to an increased tolerance for the arduous aspects of development and not, as one might fear, due to students' distancing themselves from the subject as a defense against anxiety. In our view, an important contributor to this is that the course takes place in a secure context with experienced teachers with a combined pedagogical and psychotherapeutic training and skill.

In the texts, the separate importance of the texts and the personal talk are evident, as previously shown. ${ }^{12}$ The reflective writing contributes in activating a reflective process and to provide an opportunity to see one's own reflections in written form, so to speak "outside oneself", a result supported by previous findings. ${ }^{15}$ We understand the reflective writing as entirely dependent upon the perceptions of the recipient (ie, the teacher). The talks, therefore, entail 1) motivation for writing, as well as 2) an identified recipient, who is at the same time someone the student eventually will meet and talk to. Mainly, the personal talks contribute to intellectual eye-openers as well as an understanding of the students" "Me". This self-awareness, as reported, contributes to deeper understanding of colleagues, future patients, and friends as nuanced individuals in complex environments.

The talks also provide an opportunity for the students to try out different roles; the role of a student, doctor-tobe as well as the patient role. In doing all this in a secure environment, the talks also relieve anxiety. This could be understood as follows: including one's own body when studying anatomy will lead to increased "body-awareness"; if the student does not actually involve his or her own body (eg, feeling the way muscles actually feel like), it is difficult to learn about the body in general - body awareness contributes to a deeper understanding of anatomy as a subject. Conversely, by including the self (through self-reflection) studying psychology will lead to increased self-awareness. By reflecting on one's experiences, relational patterns, and other aspects of the psyche in relation to psychological concepts, the students gain a deeper understanding of psychology. This way, psychology studies lead to not only knowledge about the subject psychology but also to self-awareness. Self-awareness, as reported by the students, helps the students understand themselves as persons as well as future doctors; it also leads to an increased understanding of colleagues, future patients, and friends as nuanced individuals in complex environments. ${ }^{5}$ We understand this process as a step toward becoming doctors with both formal skills and preferred personality traits, described in national curricula $^{14}$ and previous research. ${ }^{3}$

In our view, it is reasonable to assume that using personal talks as didactic element in this specific environment poses certain demands on the teacher. The conditions will entail multiple positions for both teachers and students during the course. For students it is a matter of interchangeably assuming the roles of student, doctor-to-be, and patient. In our view, this also requires teachers to be flexible as they must alternate between the roles of researcher, teacher, and therapist. When taking these considerations into account we propose specific recommendations regarding teachers' competences and ethics. The role of teacher will include the elements of guiding and telling, while at the same time taking the course curriculum into account; the role of therapist will include the careful balancing between support and confrontation; the role of researcher will include both knowledge of the subject itself, as well taking a critical view of one's own work. Students in the current study describe this experience as meaningful in relation to their own future work, having had first-hand experience of the vulnerable position of the patient, leading to insights valuable for the understanding and appreciation of their future patients. The students' reports of experiencing being a "patient in therapy" also lead to specific ethical considerations: the course is taking place in a context that is simultaneously clinical and academic; the teachers are trained psychologists or medical practitioners with psychotherapeutic training and the talk has elements that are therapy-like. While it may be obvious, it nevertheless leads to the subject of patient safety. Elements like these require teachers to act with respect and seriousness. Teachers need to establish a proper therapeutic framework, be aware of their own personal and educational limitations. They also need to address the fact the course may trigger specific psychological problems in individual students. The faculty needs to provide the necessary services or referrals whenever this happens. 
It is interesting to note that the students themselves report that studies in psychology yield the expected effects. We wish, without wanting to diminishing the importance of actual skills and eye-openers provided by the course, to emphasize that the combination of reflective writing and personal talks with teaching as usual have resulted in narratives of development, individual as well as for the entire group ("the class"). Further, these narratives regarding one's own development are clearly reported as related to increased understanding of others. In our view, this study established that our format of teaching psychology in medical training, is at the same time regular studies as well as a challenging process toward personal development, mirroring the view that knowing oneself is an essential tool for life. ${ }^{7}$ This teaching approach entails a redistribution of teacher-time from classic cathedral- and seminar teaching to an increased focus on inspiration, self-reflection, and personal talks. Even though no conventional time/cost-analysis has been performed, we believe that the approach is somewhat more expensive than conventional approaches.

\section{Methodological considerations}

There is a risk for bias, confirming one's own pre-suppositions, when researching on one's own process. In this study, all authors were also teachers involved in lecturing as well reflective talks. An open reflective process and awareness regarding the risk for bias is therefore a prerequisite for studies such as these. Another risk with qualitative research regards the risk for overgeneralization. This requires careful interpretation of results and focusing on how researchers understand what is said by the participants in the study. A third important aspect pertains to trustworthiness. ${ }^{19}$ Careful description of context of the participants and the research process leads to higher degree of transferability. The authors acknowledge the risk for misinterpretation of results from the present study, which may include critique regarding confounding variables influencing the results, eg, unmeasured variables during the course may as well have been a part of the reported gaining of self-knowledge. In the aim of gaining trustworthiness for this qualitative study, the authors (we) have tried to describe the course, the context, and the analysis procedure, with a high degree of transparency. Further, due to the format of the course and the scope of the study, it is unclear which factors influenced the students' writing. However, being a qualitative study, the scope has been to investigate the choices of students' themes in a required take-home, reflective writing assignment. Much effort has been placed, during the course itself and during the study, to ensure that the content of the texts are treated with respect and confidentiality, and that the text and/or following reflective talk will have no negative impact for the individual student.

In sum, while reflection and increase in self-awareness seems to take place we do not know whether the teaching format presented in this study causes increases in reflective ability. Further research, using quantifiable measures to ascertain self-knowledge, is required to understand causality and the involved mediating processes. We also recommend longitudinal studies investigating the long-term impact of the course. While reflective ability is assumed to be an important part of medical training, it is not always supported in the curriculum. In this sense, the medical training may become a hindrance or may, at least, fail to promote development. ${ }^{18}$ The results of this study show that students report that studying medical psychology in Umeå indeed promotes increased knowledge as well as personal development, leading to a greater understanding of others. Such skills have been called for as highly important for General Practitioners and other medical health professionals ${ }^{7,21}$ and are also stated in the National curriculum for medical teaching in Sweden. We argue that, in order to fully make use of psychology in training medical health professionals, university teachers should strive to treat psychology as regular studies as well as a challenging process toward personal development.

\section{Disclosure}

The authors declare that there are no conflicts of interest.

\section{References}

1. O'Sullivan H, van Mook W, Fewtrell R, Wass V. Integrating professionalism into the curriculum. Med Teach. 2012;34:155-157.

2. Morihara SK, Jackson DS, Chun MBJ. Making the professionalism curriculum for undergraduate medical education more relevant. Med Teach. 2013;35(11):908-914.

3. Rogers W, Ballantyne A. Towards a practical definition of professional behavior. J Med Ethics. 2010;36(4):250-254.

4. Chur-Hansen A, Carr JE, Bundy C, Sanchez-Sosa JJ, Tapanya S, Wahass SH. An International perspective on behavioral science education in medical schools. J Clin Psychol Med Settings. 2008;15:45-53.

5. Ring JM. Psychology and medical education: collaborations for culturally responsive care. J Clin Psychol Med Settings. 2009;16:120-126.

6. Saunders PA, Trachtenberg RE, Chaterji R, et al. Promoting selfawareness and reflection through an experimental mind-body skills course for first year medical students. Med Teach. 2007;29:778-784.

7. Urdang E. Awareness of self - a critical tool. Soc Work Educ. 2010; 29(5):523-538.

8. Driessen E, van Tartwijk J, Dornan T. The self critical doctor: helping students become more reflective. $\mathrm{Br}$ Med J. 2008;336:827-830.

9. Coulehan J, Granek IA. Commentary: "I hope I'll continue to grow": rubrics and reflective writing in medical education. Acad Med. 2012;87(1):8-10.

10. Aronson L, Niehaus B, Lindow J, Robertson PA, O'Sullivan PS. Development and pilot testing of a reflective learning guide for medical education. Med Teach. 2011;33:e515-e521. 
11. Kanthan R, Senger J-LB. An appraisal of students' awareness of "selfreflection" in a first-year pathology course of undergraduate medical/ dental education. BMC Med Educ. 2011;11(67):1-11.

12. Sandars J. The use of reflection in medical education: AMEE Guide No 44. Med Teach. 2009;31:685-695.

13. Wald HS, Borkan JM, Scott Taylor J, Anthony D, Reis SP. Fostering and evaluating reflective capacity in medical education: developing the REFLECT rubric for assessing reflective writing. Acad Med. 2012;87: 41-50.

14. Sundbom E, Andersson S-O, Semb O, Kaiser N. Reflective writing and personal talks in medical training: experiences from a new feature in the medical psychology course [Reflektivt skrivande och personligt samtal i läkarutbildningen: Erfarenheter från nya moment i kursen Medicinsk psykologi]. J Swed Med Assoc (Läkartidningen). 2013;110:CA4E. Swedish.

15. Warin J, Muldoon J. Wanting to be 'known': redefining self-awareness through an understanding of self-narration processes in educational transitions. Br Educ Res J. 2009;35(2):289-303.
16. Rodgers C. Defining reflection: another look at John Dewey and reflective thinking. Teach Coll Rec. 2002;104(4):842-866.

17. Dewey J. Democracy and Education - an Introduction to the Philosophy of Education. New York: MacMillan; 1916.

18. Chen DCR, Kirshenbaum DS, Yen J, Kirshenbaum E, Aseltine RH. Characterizing changes in student empathy throughout medical school. Med Teach. 2012;34:305-311.

19. Graneheim UH, Lundman B. Qualitative content analysis in nursing research: concepts, procedures and measures to achieve trustworthiness. Nurse Educ Today. 2003;24:105-112.

20. Larkin M, Watts S, Clifton E. Giving voice and making sense in interpretative phenomenological analysis. Qual Res Psychol. 2006;3(2): 102-112.

21. Charon R, Hermann N. Commentary: a sense of story, or why teach reflective writing? Acad Med. 2012;87:5-7.

\section{Publish your work in this journal}

Advances in Medical Education and Practice is an international, peerreviewed, open access journal that aims to present and publish research on Medical Education covering medical, dental, nursing and allied health care professional education. The journal covers undergraduate education, postgraduate training and continuing medical education including emerging trends and innovative models linking education, research, and health care services. The manuscript management system is completely online and includes a very quick and fair peer-review system. Visit http://www.dovepress.com/testimonials.php to read rea quotes from published authors.

Submit your manuscript here: http://www.dovepress.com/advances-in-medical-education-and-practice-journal 